\title{
Is wearable technology an activity motivator, or a fad that wears thin?
}

\author{
Jo Salmon ${ }^{1,2}$, Nicola D Ridgers ${ }^{1}$
}

Activity monitors may be useful for encouraging healthier lifestyles in people of all ages

$\mathrm{n}$ this issue of the $M J A$, Ewald and his co-authors report on the association between increases in daily step counts and the reduced need for hospital care among older Australians. ${ }^{1}$ Their findings confirm something international experts widely acknowledge: increasing population levels of physical activity is critical for reducing the global burden of diseases such as coronary heart disease, type 2 diabetes, and breast and colon cancers. ${ }^{2}$ With fewer than $50 \%$ of Australian adults meeting current physical activity guidelines of at least 150 minutes of moderate intensity activity per week, ${ }^{3}$ the biggest challenge faced by clinical and public health practitioners is how to increase activity levels in our largely sedentary population.

Wearable technology (eg, activity monitors such as Fitbit, Garmin, iWatch etc.) may provide the motivation needed to increase physical activity, especially among those at risk of hospitalisation. Twenty per cent of the Australian adult population (10\% of those aged 65 or more) own some form of wearable technology. ${ }^{4}$ The popularity, mass market appeal, pervasiveness, and widespread availability of wearable devices, combined with their decreasing cost, provide significant opportunities for promoting physical activity in the broader community.

But can these devices increase and maintain physical activity levels in the long term? One-third of American consumers who own wearable technology stop using it after 6 months, but the underlying reasons are poorly understood. ${ }^{5}$ Did the wearers meet their goals, or did they have trouble using the technology? Most research has focused on device validity and reliability when measuring physical activity, energy expenditure and sleep in younger adult populations; a good level of validity for step measurements has been reported. ${ }^{6}$ One review that identified 11 studies in which wearable technologies have been used in physical activity interventions reported significant increases in overall activity levels.'

However, the overall effect of such devices on the health and physical activity levels of older adults is largely unknown. Wearable activity monitors are perceived as acceptable and useful by adults aged 70 or more, and older people and those with chronic illnesses are able to use these devices. ${ }^{8}$ While users may need help with setting up their device and understanding the data it collects, ${ }^{8}$ initially focusing on step data may help older adults to familiarise themselves with their operation.

Wearable technology provides a ready means for self-monitoring of clinical and behavioural data in real time, ${ }^{7}$ long regarded by health behaviour change scientists as critical for the adoption (or cessation) of particular behaviours. Researchers have integrated these technologies into different interventions to increase activity

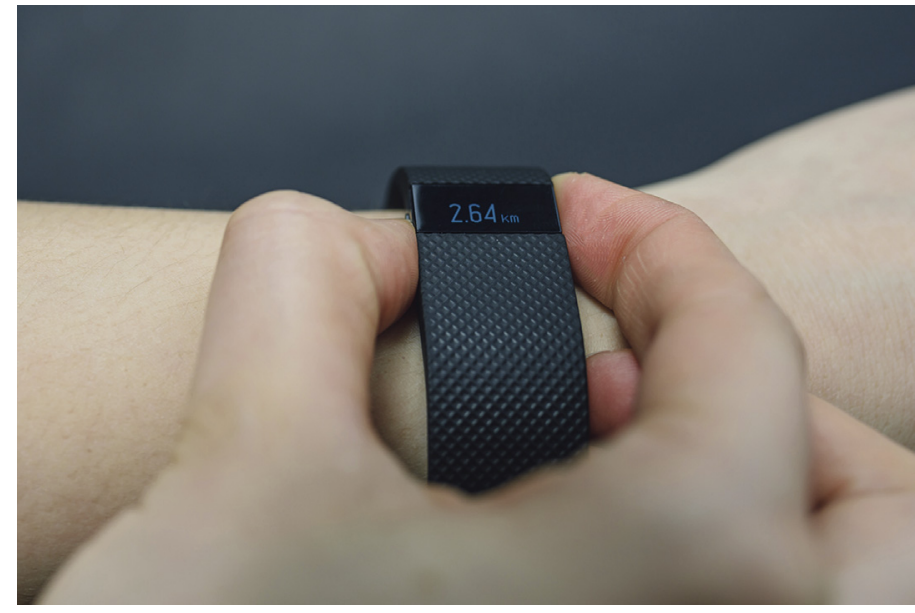

levels. A comparison of three intervention strategies (activity monitor, monitor plus cash incentives, monitor plus charity incentives) in 800 Singapore workers found that the activity monitor alone and the monitor plus charity incentives groups were significantly more active (37 and 32 minutes/week respectively) than a control group (no tracker or incentives). ${ }^{9}$ In contrast, a 24-month randomised control trial in the United States involving 471 adults compared weight loss and changes in body composition, fitness, physical activity, and dietary intake after randomisation to one of two interventions; each included group and telephone counselling, text message prompts, and website study materials. After 12 months, all participants commenced selfmonitoring on a website of their diet and physical activity, while the "enhanced intervention" group also received a wearable device. Both groups experienced significant weight loss $(3.5 \mathrm{~kg}$ and $5.9 \mathrm{~kg}$ in the enhanced and standard intervention groups respectively) and increased physical activity levels, but there were no significant differences between the two groups, possibly because both had employed self-monitoring, albeit in different forms. ${ }^{10}$

Several important messages are currently emerging from physical activity and health research. While individuals will monitor their own activity over time with wearable technology, which is important for their adopting a new physical activity or exercise regimen, the devices also have the potential to enhance the likelihood of maintaining increases in physical activity in the longer term. Features that may facilitate sustained improvement include:

- an accompanying app that enables the wearer to easily track their activity and to receive feedback relevant to set goals;

- social support from family and health professionals;

- opportunities to motivate, educate and individually tailor programs;

- prompts for desirable activity behaviours; and

- the ability to track other health behaviours and outcomes (eg, diet, weight, heart rate). 
Further investigation of wearable technology is needed, particularly in different population groups, with the aim of identifying the key factors for enhancing sustained changes in physical activity. We need to identify how these devices can be integrated into clinical practice in order to improve health outcomes. But for health practitioners with sedentary patients looking for assistance with becoming more active, a wearable activity monitor would be a good first step.

Acknowledgements: Jo Salmon is supported by a National Health and Medical Research Council Principal Research Fellowship (APP1026216).

Competing interests: No relevant disclosures.

Provenance: Commissioned; externally peer reviewed.

(c) 2017 AMPCo Pty Ltd. Produced with Elsevier B.V. All rights reserved.

1 Ewald BD, Oldmeadow C, Attia JR. Daily step count and the need for hospital care in subsequent years in a community-based sample of older Australians. Med J Aust 2017; 206: 126-130.

2 Lee IM, Shiroma EJ, Lobelo F, et al. Effect of physical inactivity on major noncommunicable diseases worldwide: an analysis of burden of disease and life expectancy. Lancet 2012; 380: 219-229.
3 Australian Bureau of Statistics. 4364.0.55.004. Australian Health Survey: physical activity, 2011-12. July 2013. http://www.abs.gov.au/AUSSTATS/abs@.nsf/ DetailsPage/4364.0.55.0042011-12?OpenDocument (accessed Nov 2016).

4 Pureprofile. Wearables work - Australians more active with fitness trackers [media release]. 23 Apr 2015. http://businesses.pureprofile.com/news/wearables-workaustralians-more-active-with-fitness-trackers (accessed July 2016).

5 Ledger D, McCaffrey D; for Endeavour Partners. Inside wearables. How the science of human behavior change offers the secret to long-term engagement [report]. Jan 2014. http://endeavourpartners.net/assets/Endeavour-Partners-Wearablesand-the-Science-of-Human-Behavior-Change-Part-1-January-20141.pdf (accessed July 2016)

6 Evenson KR, Goto MM, Furberg RD. Systematic review of the validity and reliability of consumer-wearable activity trackers. Int J Behav Nutr Phys Act 2015; 12: 159.

7 Lewis ZH, Lyons EJ, Jarvis JM, Baillargeon J. Using an electronic activity monitor system as an intervention modality: a systematic review. BMC Public Health 2015; 15: 585.

8 Mercer K, Giangregorio L, Schneider E, et al. Acceptance of commercially available wearable activity trackers among adults aged over 50 and with chronic illness: a mixedmethods evaluation. JMIR Mhealth Uhealth 2016; 4: e7.

9 Finkelstein EA, Haaland BA, Bilger M, et al. Effectiveness of activity trackers with and without incentives to increase physical activity (TRIPPA): a randomised controlled trial. Lancet Diabetes Endocrinol 2016; 4: 983-995.

10 Jakicic JM, Davis KK, Rogers RJ, et al. Effect of wearable technology combined with a lifestyle intervention on long-term weight loss: the IDEA randomized clinical trial. JAMA 2016; 316: 1161-1171. 